\title{
Clinical Picture
}

\section{Chediak-Higashi syndrome: pathognomonic feature}

Henedina Antunes, Ângela Pereira, Isabel Cunha

A 2-year-old girl presented to us with recurrent infections, hepatosplenomegaly, and photophobia. On examination she had blond hair with a metallic sheen. The blood smear showed giant lysosomes in the white blood cells (figure) and we diagnosed Chediak-Higashi syndrome, a rare autosomal recessive disease (gene CHS1/LYST at 1q42.1-2). There have been around 200 cases reported, and giant cytoplasmic granules are pathognomonic. Death often occurs before the age of 7 years because of the so-called accelerated phase, with hepatosplenomegaly, lymphadenopathy, and pancytopenia or severe recurrent bacterial infections.

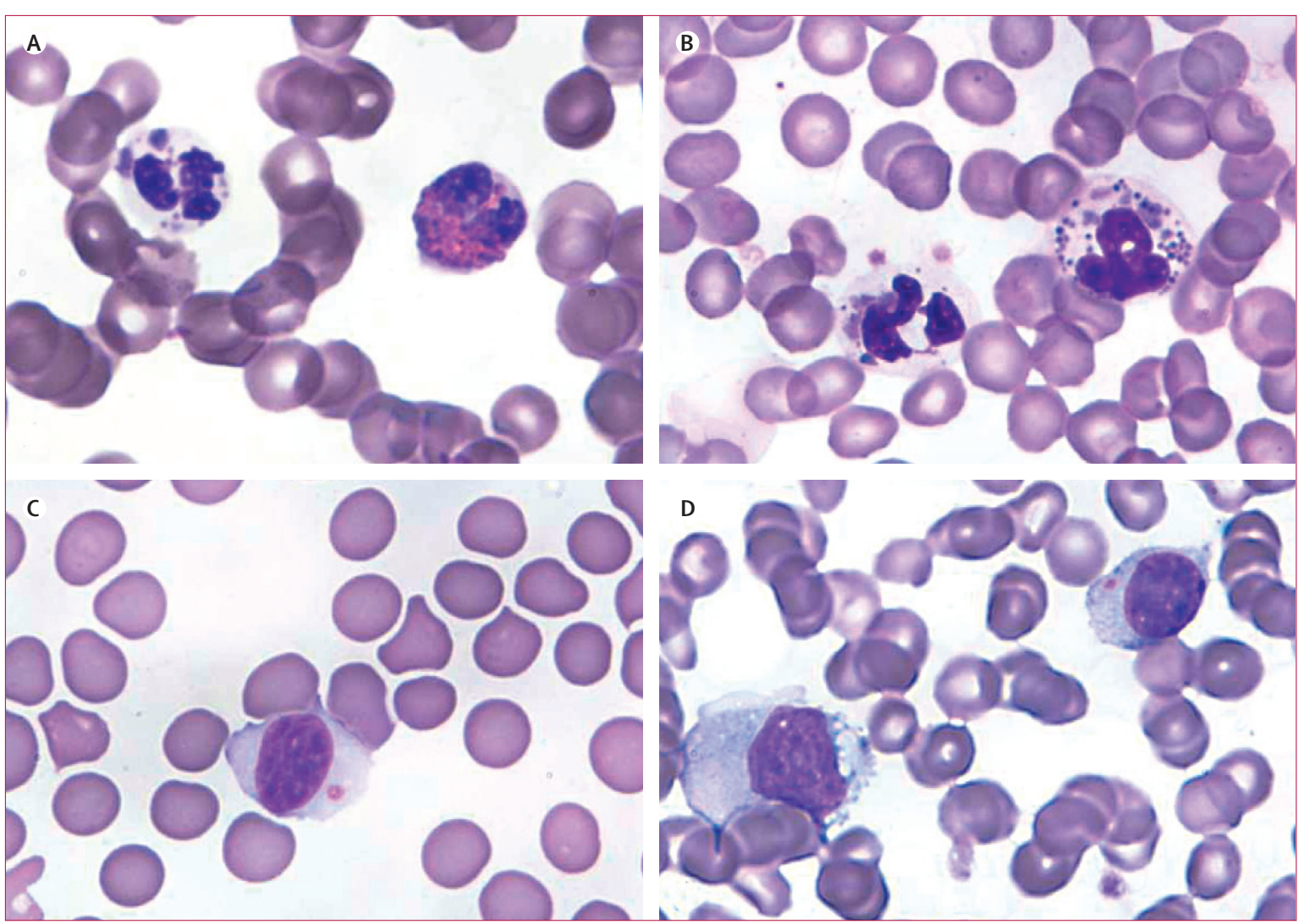

Figure: Chediak-Higashi syndrome

Blood film showing pathognomonic giant cytoplasmic granules in neutrophils and eosinophils (A), neutrophils (B), and lymphocytes (C, D).
The laboratory diagnosis was supported by partial oculocutaneous albinism and typical microscopic granules in hair shafts.

A new mutation was identified and our patient was found to be homozygous for a sequence change in the LYST gene: p.G3583R:c.10747G>. She currently waits for a compatible haemopoietic cell transplantation donor. Her parents and brother are not HLA-identical.

Our patient is now 7 years old, and is well, without serious infections, and with normal neurological function, which might be related to a milder clinical phenotype.
@@

Published Online March 29, 2013 http://dx.doi.org/10.1016/ S0140-6736(13)60020-3

Paediatrics Department Hospital de Braga, Braga, Portugal (Prof H Antunes PhD, ÂPereira MD, I Cunha MD); Life and Health Sciences Research Institute (ICVS), School of Health Sciences, University of Minho, Braga, Portugal (Prof H Antunes); and ICVS/3B's-PT Government Associate Laboratory, Braga/ Guimarães, Portugal (Prof H Antunes)

Correspondence to: Prof Henedina Antunes, Paediatrics Department, Hospital de Braga, Sete Fontes, S Victor, Apartado 2056, 4701-901,Braga, Portugal henedinaantunes@gmail.com 